\title{
RECYCLING OF WASTE TIRES FOR BIO CRUDE FUEL PRODUCTION THROUGH A PYROLYSIS SYSTEM
}

\author{
'Dunya A. Khalaf ${ }^{1}$
}

Zaidoon N. Aboodi ${ }^{1}$

\author{
Saadi M. Daher ${ }^{2}$
}

1) Environmental Engineering Department, College of Engineering, Mustansiriyah University, Baghdad, Iraq

2) Environmental research center, University of Technology, Baghdad, Iraq

\begin{abstract}
Recycling of solid waste is one of the most valuable method which is used in worldwide for integral solid waste management. Waste tires are considered to be a source of energy and valuable chemical products. In this study waste tire samples of mixed types (passenger, truck, and heavy vehicles etc.) were decomposed thermally in a fixed bed reactor made up of stainless steel placed inside an electrical heater. Thermal pyrolysis on tire waste samples with (1-2) $\mathrm{cm}$ of particle size was carried out at temperatures of $330^{\circ} \mathrm{C}, 430^{\circ} \mathrm{C}, 530^{\circ} \mathrm{C}$, and $630{ }^{\circ} \mathrm{C}$ under Argon flow rate of $0.5 \mathrm{~L} / \mathrm{min}$ and retention time of $15 \mathrm{~min}$ to study the effect of temperature on the distribution of pyrolysis products yield. Three main products were obtained by tire pyrolysis pyro oil, gas, and solid residue. Chemical compositions of pyrolysis oil product were characterized by Gas chromatography mass and Fourier transform infrared spectroscopy analyses, it is a complex mixture of alkane, alkene, cycloalkane, cycloalkane, alcohol, ester, and aromatic compounds which are preferable in fuel. If found that a limonene compound occupies the largest proportion of the oil product which is considered as a more valuable compounds.
\end{abstract}

Keywords: waste tire, pyrolysis, tire oil, Limonene.

\section{Introduction}

Solid waste management (SWM) is required and challenging duty in worldwide countries [1].

Waste tires are the most challenging risky waste which threating countries. They can be defined as tires which exceeding the life of their production or that can no longer safe to be use [2].

Open dumping of landfill sites were the common method for disposing waste tires over the years, due to their bulky nature, and non-degradability that would take up valuable land space [3] and [4]. Waste tire is a polymer solid waste which is non- biodegradable due to their complex mixture of chemicals, which include mainly natural and synthesis rubber, carbon black, organic and inorganic compounds, and steel cord [5]. Management of waste tire still be increasing the crisis in most countries due to absence of active legislations, inadequate funding, and poor organization [6]. The huge amount of waste generated currently required for an urgent move towards a circular economy systems, reducing generation of waste and eliminating the extraction of non-renewable resources [7].

Several processing for waste tire recycling are used such as incineration, grinding, retreading, and reclaiming etc. however all of these processes have some drawbacks [8]. Find an alternative source of recycling waste tire is a sustainable approach for the future aspects. One

*Corresponding Author: dunyaahmed82@gmail.com 
of main techniques which is used in recycling waste tires is the pyrolysis process that allows to convert the non- degradable materials to a condensable liquid, non- condensable gas, and solid residue [9]. A recycling technique of pyrolysis which is an endothermic process, allowing materials for converting into pyro oil, pyro gas, and pyro char [10]. Sources of raw materials involved in pyrolysis process include municipal solid waste, agricultural by products, wood and plastic waste, pyrolysis of waste tire was studied at temperatures ranging of (350-800) ${ }^{\circ} \mathrm{C}$. they found that the optimum operation temperatures are between $500{ }^{\circ} \mathrm{C}$ and $600{ }^{\circ} \mathrm{C}$ [11]. The pyrolysis process can be carried out via catalytic and thermal routes [12]. Pyrolysis process can defined as a thermal decomposition under high temperature with an inert atmosphere. Its application can be used to convert non degradable waste like plastic to useful oil [13]. Waste tires have a high content of energy that increased their utilization in wide different energy applications such as a direct combustion in paper industries, [14] or cement kilns [15]. Waste tire pyrolysis process recovering high value products [16]. Tire pyrolysis oil (TPO) is suitable to be used as an alternative ignition fuel in the engines of diesel [17], also used for a valuable chemicals derivative such as limonene compound which has advantageous properties in medicinal. [18]. While pyro gas can be using as hydrogen, and fuel manufacturing [19]. Pyrolysis process was one of the best methods to treat waste tire under solid waste management technique. De-moisturizing, desulphurization, and distillation process were carried out for purification of TPO [20]. It is performed in an inert atmosphere (oxygen-free), the production of toxic gases as COx, NOx, and SOx is decreased in comparison with the traditional incineration [21]. This study aims to reduce waste tire accumulation by using pyrolysis process, which ensures a safe disposal of solid waste and provides a new source of fuel.

\section{Materials and Method}

\subsection{Raw material}

Tire samples were collected as a raw material from AL-Diwaniyah tires factory which they are a mixture of different shredded tire types (truck, passenger, etc.). The steel was separated from rubber to be used in pyrolysis as shown in Figure (1) guidelines without any deviation. Physical properties such as Moisture content and particle size of raw material were measured. Moisture content was determined according to the ASTM 1756-01 standard procedure. Waste tire was heated in to an oven at constant temperature of $105{ }^{\circ} \mathrm{C}$ for 3 hours with keeping weighing up to $0.1 \mathrm{mg}$ in repeating rounds until constant mass was obtained. Then the samples were placed in the desiccators to be cooled down before reweighed. The difference in weight presented the percentage of moisture content of the sample at a constant end mass. Particle size was measured by sieving granules device. The result is shown in able (1). Small particle size able to complete the pyrolysis in short time but the heat rate required is higher compared with larger particles [22]. Residence time inside the reactor increases when large tire particle size are used that means increasing the volume of the reactor and thus increasing the cost [23]. The high moisture content of municipal solid waste affecting the thermal treatment processes like pyrolysis. [24]. 


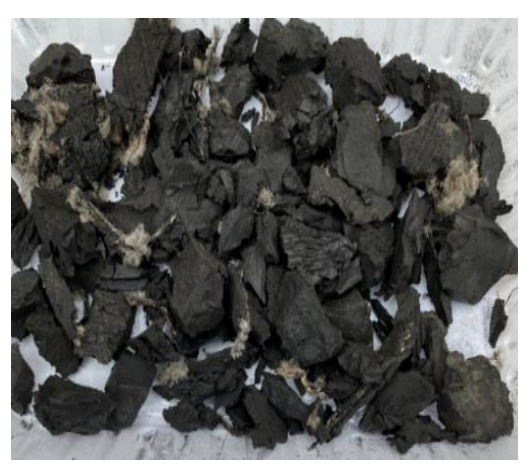

Figure 1. Waste tire sample

Table 1. Physical properties of raw material

\begin{tabular}{cc}
\hline variable & results \\
\hline $\mathrm{MC} \%$ & 0.8655
\end{tabular}

Particle size, $\mathrm{mm} \quad 10-20$

\subsection{Experimental Work}

The Pyrolysis system designed and built based on the extensive knowledge acquired in previous studies, on pyrolysis of waste tires, as shown in Figure (2). It consist of (cylindrical reactor, an electrical furnace, muffle materials, and condenser). Where the reactor was made of a stainless steel cylindrical with (depth: $220 \mathrm{~mm}$ and diameter: $132 \mathrm{~mm}$ ) provided by three openings, the first one is at the top for inert gas, the second one is for internal thermocouple and the third for the condenser. To be insure that a continuously slow stirring and uniform distribution of heat an electrical stirrer fixed in the middle of the reactor. The reactor was vertically welded to the middle of the furnace flange. The electrical furnace with dimension of height: $36 \mathrm{~cm}$, long: $50 \mathrm{~cm}$, wide: $50 \mathrm{~cm}$, covered with a loop of an electrical heater insulated by metaling box provided with bricks muffle inside it, and temperature controlling on external to achieve the desired temperatures with maximum $900{ }^{\circ} \mathrm{C}$.

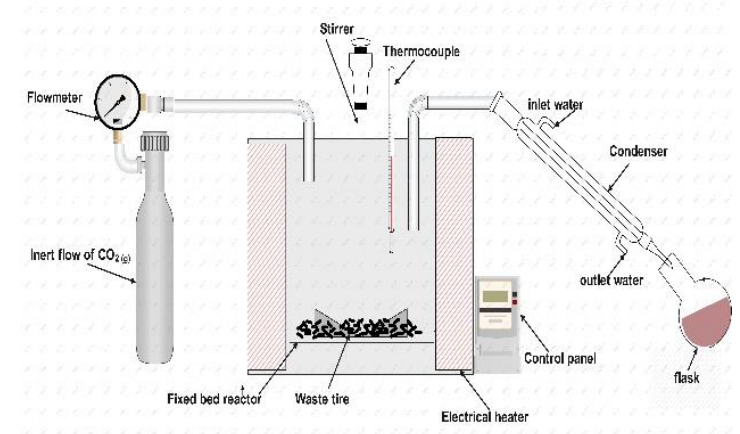

Figure 2. Schematic of tire pyrolysis system

\subsection{Pyrolysis Process}

Thermal cracking of waste tire for chips samples was achieved, at temperatures of $330{ }^{\circ} \mathrm{C}, 430{ }^{\circ} \mathrm{C}$, $530{ }^{\circ} \mathrm{C}$, and $630{ }^{\circ} \mathrm{C}$. In every Run was done, about $100 \mathrm{~g}$ of each sample was closed in the reactor. The pyrolysis oil obtained by the condensation of the organic volatile which releasing when the temperature reaches to $300{ }^{\circ} \mathrm{C}$ inside the reactor then the liquid began distilled, and collected by flask fixed at the end of condenser. Each run ending after completion process or when the liquid production through the condenser stops. These were for identification the optimum temperature and retention times inside the reactor, when the reactor have been heated the feedstock begin vaporized, the organic vapors converting into a liquid product when passing through the condenser which named pyrolysis oil. The undecomposed residue was collected from the reactor at the end of each run, and then the system was cooled down at room temperature.

\section{Results and Discussion}

\subsection{Effect of Temperature}

The yield of products from tire pyrolysis by using samples with particle size ranging of (1-2) cm, retention time of 15 min were estimated by the Eqs. of (1), (2), and (3), the results are shown in Figure (3), and Table (2) it reveals that increasing the temperature of the process from $330{ }^{\circ} \mathrm{C}$ to 630 
${ }^{\circ} \mathrm{C}$, the pyrolysis oil yield increased from $33.5 \mathrm{wt}$. $\%$ at $330{ }^{\circ} \mathrm{C}$ to highest value of 51.7 wt. $\%$ at temperature of $630{ }^{\circ} \mathrm{C}$, while the solid residue was reduced from $57.8 \mathrm{wt}$ \% to $32 \mathrm{wt} \%$ and the yield of gas product, increased linearly from 8.7 wt. $\%$ at $330{ }^{\circ} \mathrm{C}$ to $16.3 \%$ at temperature of $630{ }^{\circ} \mathrm{C}$.

The increasing in the yield of oil and the reduction in the yield of solid product with the temperature increases is compatible with [25] who investigated the thermal pyrolysis of (WT) at temperatures of $350{ }^{\circ} \mathrm{C}$ to $750{ }^{\circ} \mathrm{C}$, and [26] at temperature of $500{ }^{\circ} \mathrm{C}$ to $800{ }^{\circ} \mathrm{C}$. As well as the increasing of the yield of gas with increasing temperature is compatible with [27] who studied the pyrolysis of the waste tire (WT) at temperatures starting from $300{ }^{\circ} \mathrm{C}$ to $500{ }^{\circ} \mathrm{C}$.

$$
\begin{aligned}
& \text { oil wt. } \%=\frac{\text { weight of oil }}{\text { wieght of feed }} \times 100 \% \\
& \text { solid wt. } \%=\frac{\text { weight of solid }}{\text { wieght of feed }} \times 100 \%
\end{aligned}
$$

Gas wt. $\%=100-$ wt. $\%$ oil - wt. $\%$ solid

Table 2. Pyrolysis products yield

\begin{tabular}{cccc}
\hline $\begin{array}{c}\text { Temperature } \\
{ }^{\circ} \mathbf{C}\end{array}$ & $\begin{array}{c}\text { Oil wt. } \\
\mathbf{\%}\end{array}$ & $\begin{array}{c}\text { Solid wt. } \\
\mathbf{\%}\end{array}$ & $\begin{array}{c}\text { Gas wt. } \\
\mathbf{\%}\end{array}$ \\
\hline 330 & 33.5 & 57.8 & 8.7 \\
430 & 40.9 & 47 & 12.1 \\
530 & 50 & 35.6 & 14.4 \\
630 & 51.7 & 32 & 16.3 \\
\hline
\end{tabular}

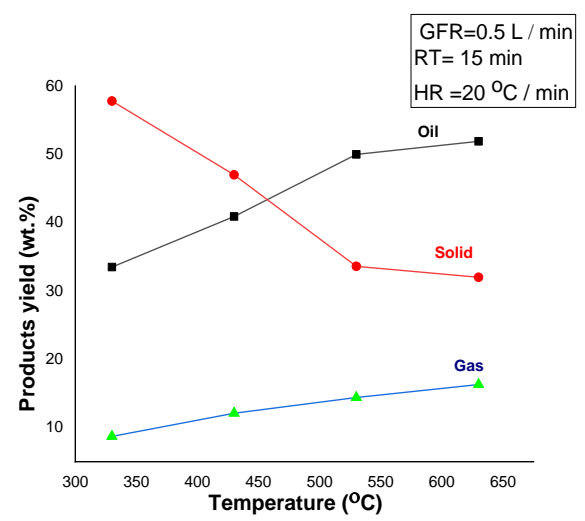

Figure 3. Effect of temperature on pyrolysis products yield from waste tire

\subsection{Gas Chromatography Mass Spectrometer (GC-MS) of Oil Product}

Pyro-oil product were identified using alkane standards $\left(\mathrm{C}_{7}-\mathrm{C}_{20}\right)$, which was obtained from Sigma Aldrich. The analyses of pyrolysis oil product which obtained at temperature of $530{ }^{\circ} \mathrm{C}$, with an inert gas (GFR) of $0.5 \mathrm{~L} / \mathrm{min}$, and a resident time (RT) of $15 \mathrm{~min}$ was quantified using Gas Chromatography mass spectrometer (GC-MSS QP 2010 plus Shimadzu), by comparing the spectral data with that in the mass spectral library, the chemical compounds identified depending on the similarity index (SI), and peak area of total ion chromatogram (TIC). The results of the investigated sample is shown in Table (3) which clarified the chemical compositions of oil product. It contained about 70 compounds as shown in Table (4), the data of tire pyrolysis oil (TPO) are a very complex mixture of organic compounds of $\mathrm{C}_{8}-\mathrm{C}_{24}$ and these results match those observed in earlier studies [28] and [29]. The greatest peak was to [Cyclohexane, 1, 2-bis (1-methylethenyl)-, trans] $\mathrm{C}_{10} \mathrm{H}_{16}$, it was $28.9 \%$. Furthermore, the oxygenated compounds from thermal pyrolysis was around $33.62 \%$ such as $\mathrm{C}_{14} \mathrm{H}_{28} \mathrm{O}_{3} \mathrm{~S}$, $\mathrm{C}_{18} \mathrm{H}_{36} \mathrm{O}_{3} \mathrm{~S}, \mathrm{C}_{8} \mathrm{H}_{18} \mathrm{O}_{2} \mathrm{~S}, \mathrm{C}_{11} \mathrm{H}_{22} \mathrm{O}_{3} \mathrm{~S}$, etc. it is due to the vulcanization process where the sulfur is 
added to tires to improve the stability of product's, heat resistance and hardness also making it more beneficial for application in the industry [30]. The nitrogenated compounds are also oxygenated compound exist in the pyro- oil like a quinoline and [2-Piperidinone, N-[4bromo-n-butyl] but in low amount.

Table 3. Chemical composition in tire pyrolysis oil

\begin{tabular}{cc}
\hline Compositions & Area \% \\
\hline Alkane & 3.39 \\
Alkene & 17.92 \\
Cycloalkane & 29.43 \\
Cycloalkene & 6.01 \\
Aromatic & 9.38 \\
Easter & 18.34 \\
Ketone & 4.09 \\
Alcohol & 8.04 \\
Others & 3.4 \\
Total & 100 \\
Hydrocarbons & 66.38 \\
Oxygenated & 33.62 \\
Total & 100 \\
\hline
\end{tabular}

\subsection{Fourier Transform Infrared Spectroscopy (FTIR) of Oil Product}

FTIR was conducted to identify the chemical functional groups present in tire pyrolysis oil. Figure (4) displays the main functional groups presented in tire pyrolysis oil. The sharp medium peak in the (FTIR) spectrum is indicated to a stretch bond of $\mathrm{C}=\mathrm{C}$ at $1635 \mathrm{~cm}^{-1}$ confirms the presence of alkenes and that proven in the results of GC-MS analysis as shown in the Table (3) the percentage was 17.92, In addition, a broad medium peak between the range of wavenumber between $3250 \mathrm{~cm}^{-1}$ and $3400 \mathrm{~cm}^{-1}$, indicating the existence of nitrogen compounds which represent by stretching bond of $\mathrm{N}-\mathrm{H}$. The results of GC-MS analysis in table (4) approved this. Figure (4) shows a broad medium peak in the wavenumber range $(500-600) \mathrm{cm}^{-1}$ which refers to halogen compounds represent by the carboniodine, carbon-bromine and carbon-chlorine bonds which are in the mode of stretching and vibration. Whilst, the presence of a small peaks in the wavenumber ranging between $1250 \mathrm{~cm}^{-1}$ and $2000 \mathrm{~cm}^{-1}$ proving the existence of aromatic rings in the portions of (TPO) and this fact is consistent with [31].

The range of distinguishing vibrational in the (FTIR) displayed the compounds of sulfur from $1300 \mathrm{~cm}^{-1}$ to $1440 \mathrm{~cm}^{-1}$ as sulfone and sulfoxide derivatives. The tire pyrolysis oil product shows distinguishing of vibrational mode at the range of $1415 \mathrm{~cm}^{-1}$ for the stretching bond of $\mathrm{S}=\mathrm{O}$ for sulfuric compounds such as $\mathrm{C}_{14} \mathrm{H}_{28} \mathrm{O}_{3} \mathrm{~S}$, $\mathrm{C}_{18} \mathrm{H}_{36} \mathrm{O}_{3} \mathrm{~S}, \mathrm{C}_{14} \mathrm{H}_{30} \mathrm{O}_{3} \mathrm{~S}$ and $\mathrm{C}_{24} \mathrm{H}_{48} \mathrm{O}_{3} \mathrm{~S}$ as shown in Table (4) The amount of sulfuric compounds was $19.19 \%$ of the oxygenated compounds $33.62 \%$ according to the percentage quantified area for identified peak for all sulfuric compounds.

The mechanisms of producing the sulfur compounds are contrast according to the temperature, reactor type, and the heating rate [32]. The generating of sulfuric compounds in tire pyrolysis oil is due to Benzothiazol compound which is used as an accelerator in the industry of tires [33].

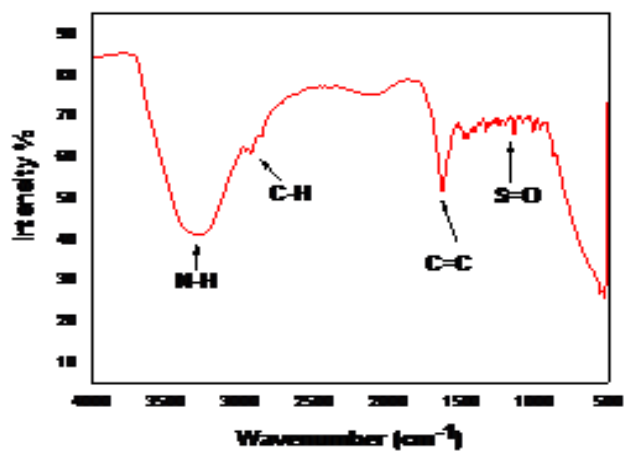

Figure 2. FTIR spectrum of the oil product 
Table 4. Chemical composition of tire pyrolysis oil

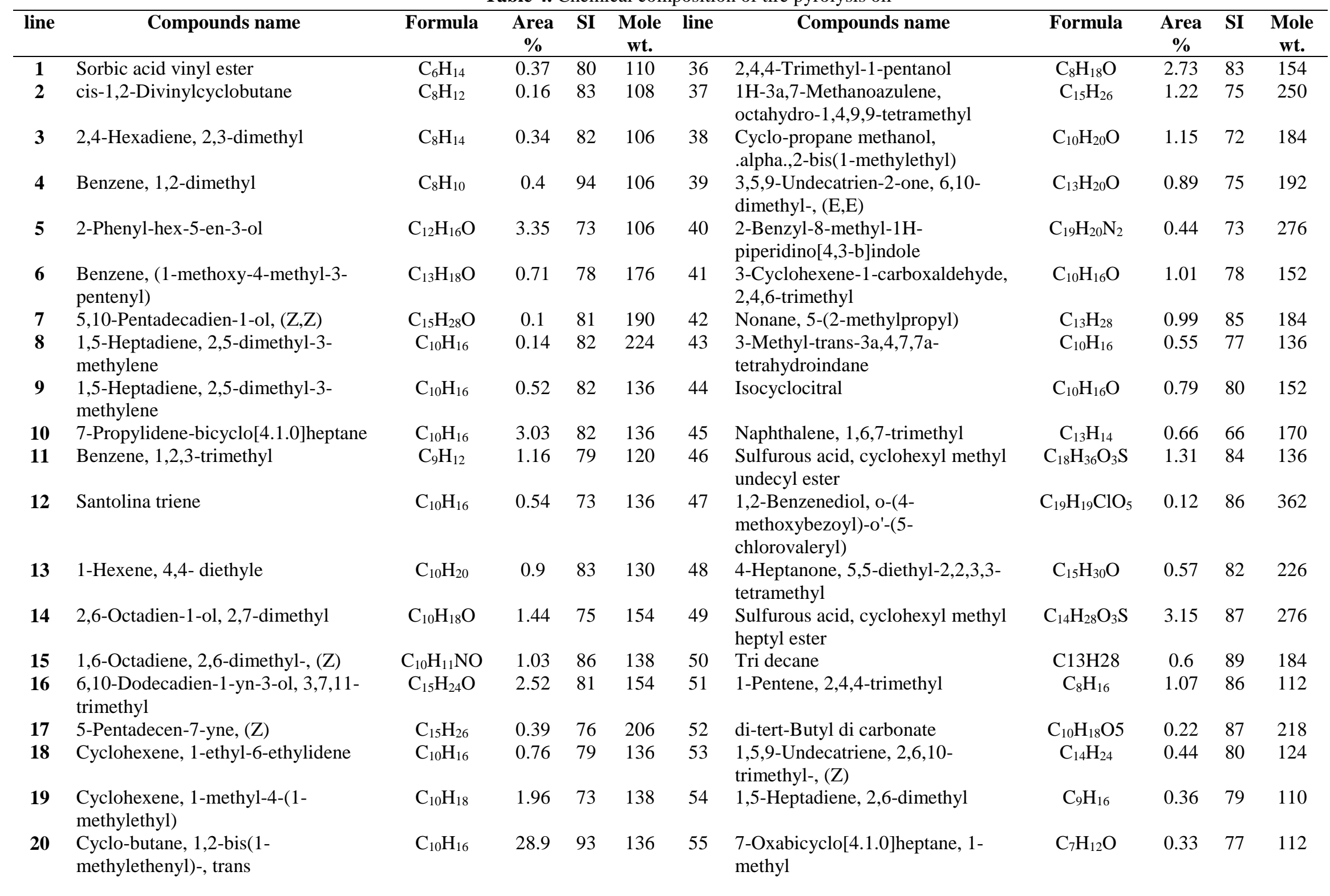




\begin{tabular}{|c|c|c|c|c|c|c|c|c|c|c|c|}
\hline 21 & 1-Methylene-2-vinylcyclopentane & $\mathrm{C}_{8} \mathrm{H}_{12}$ & 0.37 & 73 & 150 & 56 & $\begin{array}{l}\text { Bis (2-ethylhexyl) methyl } \\
\text { phosphate }\end{array}$ & $\mathrm{C}_{13} \mathrm{H}_{26} \mathrm{O}_{3} \mathrm{~S}$ & 1.6 & 81 & 262 \\
\hline 22 & 1-Pentene, 2,4,4-trimethyl & $\mathrm{C}_{8} \mathrm{H}_{16}$ & 1.76 & 79 & 112 & 57 & 1-Pentene, 4,4-dimethyl & $\mathrm{C}_{13} \mathrm{H}_{26} \mathrm{O}_{3} \mathrm{~S}$ & 0.8 & 75 & 262 \\
\hline 23 & $\begin{array}{l}\text { o-Toluic acid, 2,7-dimethyloct-7-en- } \\
\text { 5-yn-4-yl ester }\end{array}$ & $\mathrm{C}_{10} \mathrm{H}_{14}$ & 0.33 & 75 & 134 & 58 & $\begin{array}{l}\text { Sulfurous acid, cyclohexyl methyl } \\
\text { isobutyl ester }\end{array}$ & $\mathrm{C}_{11} \mathrm{H}_{22} \mathrm{O}_{3} \mathrm{~S}$ & 2.68 & 87 & 234 \\
\hline 24 & $\begin{array}{l}\text { Cyclohexene, 4-methyl-3-(1- } \\
\text { methylethylidene) }\end{array}$ & $\mathrm{C}_{10} \mathrm{H}_{16}$ & 1.49 & 79 & 136 & 59 & 1-Pentene, 2,4,4-trimethyl & $\mathrm{C}_{8} \mathrm{H}_{16}$ & 0.86 & 83 & 112 \\
\hline 25 & $\begin{array}{l}\text { Benzene, 1-methyl-4-(1- } \\
\text { methylethenyl) }\end{array}$ & $\mathrm{C}_{10} \mathrm{H}_{12}$ & 1.32 & 87 & 132 & 60 & $\begin{array}{l}\text { Sulfurous acid, cyclohexyl methyl } \\
\text { heptyl ester }\end{array}$ & $\mathrm{C}_{14} \mathrm{H}_{28} \mathrm{O}_{3} \mathrm{~S}$ & 1.09 & 83 & 276 \\
\hline 26 & 1-Pentene, 2,4,4-trimethyl & $\mathrm{C}_{8} \mathrm{H}_{16}$ & 1.41 & 79 & 112 & 61 & $\begin{array}{l}\text { 2-Thiopheneacetic acid, 3-tridecyl } \\
\text { ester }\end{array}$ & $\mathrm{C}_{19} \mathrm{H}_{32} \mathrm{O}_{2} \mathrm{~S}$ & 0.69 & 80 & 324 \\
\hline 27 & $\begin{array}{l}\text { Bicyclo[3.1.0]hex-2-ene, 4,4,6,6- } \\
\text { tetramethyl }\end{array}$ & $\mathrm{C}_{10} \mathrm{H}_{16}$ & 0.38 & 76 & 136 & 62 & $\begin{array}{l}\text { 3-Octyne-2,5-dione, } 6,6,7- \\
\text { trimethyl }\end{array}$ & $\mathrm{C}_{11} \mathrm{H}_{16} \mathrm{O}_{20}$ & 1.95 & 91 & 96 \\
\hline 28 & Benzothiazole & $\mathrm{C}_{7} \mathrm{H}_{5} \mathrm{NS}$ & 2.05 & 88 & 135 & 63 & $\begin{array}{l}\text { Cyclopropane methanol, .alpha.,2- } \\
\text { bis(1-methylethyl) }\end{array}$ & $\mathrm{C}_{10} \mathrm{H}_{20} \mathrm{O}$ & 1.06 & 93 & 156 \\
\hline 29 & 1H-Indene, 1,1-dimethyl & $\mathrm{C}_{11} \mathrm{H}_{12}$ & 0.42 & 69 & 144 & 64 & $\begin{array}{l}\text { Sulfurous acid, 2-ethylhexyl } \\
\text { isohexyl ester }\end{array}$ & $\mathrm{C}_{11} \mathrm{H}_{23} \mathrm{I}$ & 0.27 & 86 & 278 \\
\hline 30 & $\begin{array}{l}\text { Sulfurous acid, cyclohexyl methyl } \\
\text { heptyl ester }\end{array}$ & $\mathrm{C}_{14} \mathrm{H}_{28} \mathrm{O}_{3} \mathrm{~S}$ & 1.38 & 83 & 154 & 65 & $\begin{array}{l}\text { Sulfurous acid, cyclohexyl methyl } \\
\text { hexadecyl ester }\end{array}$ & $\mathrm{C}_{23} \mathrm{H}_{46} \mathrm{O}_{3} \mathrm{~S}$ & 0.86 & 85 & 402 \\
\hline 31 & 3-Methyl-1-hexanol & $\mathrm{C}_{7} \mathrm{H}_{16} \mathrm{O}$ & 0.38 & 75 & 140 & 66 & $\begin{array}{l}\text { Sulfurous acid, di(cyclohexyl } \\
\text { methyl) ester }\end{array}$ & $\mathrm{C}_{14} \mathrm{H}_{26} \mathrm{O}_{3} \mathrm{~S}$ & 0.27 & 66 & 274 \\
\hline 32 & Nonane, 1-iodo & $\mathrm{C}_{9} \mathrm{H}_{19} \mathrm{I}$ & 0.45 & 76 & 164 & 67 & $\begin{array}{l}\text { Sulfurous acid, cyclohexyl methyl } \\
\text { heptadecyl ester }\end{array}$ & $\mathrm{C}_{24} \mathrm{H}_{48} \mathrm{O}_{3} \mathrm{~S}$ & 2.17 & 87 & 416 \\
\hline 33 & Heptane, 2-iodo & $\mathrm{C}_{7} \mathrm{H}_{15} \mathrm{I}$ & 1.13 & 85 & 156 & 68 & 2,4,4-Trimethyl-1-pentanol & $\mathrm{C}_{8} \mathrm{H}_{18} \mathrm{O}$ & 0.53 & 80 & 130 \\
\hline 34 & $\begin{array}{l}\text { Sulfurous acid, di(cyclohexyl } \\
\text { methyl) ester }\end{array}$ & $\mathrm{C}_{11} \mathrm{H}_{12}$ & 3.31 & 88 & 154 & 69 & $\begin{array}{l}\text { Butanal, 4-[(tetrahydro-2H-pyran- } \\
\text { 2-yl)oxy] }\end{array}$ & $\mathrm{C}_{9} \mathrm{H}_{16} \mathrm{O}_{3}$ & 0.51 & 73 & 158 \\
\hline 35 & $\begin{array}{l}\text { Benzene, 1,3,5-trimethyl-2-(1,2- } \\
\text { propadienyl) }\end{array}$ & $\mathrm{C}_{12} \mathrm{H}_{14}$ & 0.7 & 70 & 154 & 70 & $\begin{array}{l}\text { 2-Thiopheneacetic acid, heptyl } \\
\text { ester }\end{array}$ & $\mathrm{C}_{13} \mathrm{H}_{20} \mathrm{O}_{2} \mathrm{~S}$ & 0.46 & 78 & 240 \\
\hline
\end{tabular}




\section{Conclusions}

The application of pyrolysis process for municipal solid waste generally and for treating the waste tire particularly has advantages for the reduction the environmental contamination and controlling the accumulation of waste tire beside that the providing a renewable source for fuel. Temperature plays a significant role on the yield of pyrolysis products it can be concluded that when the temperature was increased from $330{ }^{\circ} \mathrm{C}$ to $630^{\circ} \mathrm{C}$ shows a linearly increasing in the yields of the oil and gas while a reduction in the solid residue was observed. The Optimum operation temperature was found at temperature of $530{ }^{\circ} \mathrm{C}$ under FGR of $0.5 \mathrm{~L} / \mathrm{min}$ and resident time of 15 min, because increasing temperature up to $530^{\circ} \mathrm{C}$ does not provide more thermal conversion also from economic side. The percentage quantified area of the hydrocarbon compounds which there existing in the fuel is desired was $66.38 \%$, presented of Limonene as the major compound beside the oxygenated and sulfuric compounds of $33.62 \%$ which is not preferred and pyrolysis oil products required an appropriate chemical treating (desulfurization and deoxygenating) before they can be used as a fuel.

\section{Conflict of Interest}

The authors declare that there are no conflicts of interest regarding the publication of this manuscript.

\section{References}

1. World Health Organization. WHO. (2015). "Waste and human health: evidence and needs". In WHO meeting report, Germany, pp. 5-6.

2. Stefano F., S., Seggiani, M., Puccini, M. and Vitolo, S. (2014). "Liquid fuel production from waste tire pyrolysis and its utilization in a Diesel engine”. Fuel, 116, 399-408.
3. Islam M. Rahim, Islam, M. N., Mustafi N. N., Rahim, M. A. and Haniu, H. (2013). "Thermal recycling of solid tire wastes for alternative liquid fuel: the first commercial step in Bangladesh". Procedia engineering, vol. 56, pp. 573-582.

4. Augustine Quek, and Rajasekhar Balasubramanian (2013). "Liquefaction of waste tires by pyrolysis for oil and chemicals-A review". Journal of Analytical and Applied Pyrolysis, vol. 101, pp. 1-16.

5. Islam, M. R., Tushar, M. S. H. K., and Haniu, H. (2008). "Production of liquid fuels and chemicals from pyrolysis of Bangladeshi bicycle/rickshaw tire wastes". Journal of Analytical and Applied Pyrolysis, vol. 82, pp. 96-109.

6. Mrad M., and El Samra, R. (2020). "Waste Tire Management: Lebanon Case Study”. Journal of Waste Management Disposal.

7. Jean-Paul Peronard and Anne Gammelgaard Ballantyne. (2019). "Broadening the understanding of the role of consumer services in the circular economy: Toward a conceptualization of value creation processes". Journal of Cleaner Production, vol. 239, 118010.

8. Isabel de Marco Rodriguez, M. F. Laresgoiti, M.A Cabrero, A Torres M.J, Chomón, and B Caballero. (2001), "Pyrolysis of scrap tires". Fuel Processing Technology; vol. 72, pp. 9-22.

9. Lopez, F. A., El Hadad, A. A., Alguacil, F. J., Centeno, T. A. and Lobato, B. (2013). "Kinetics of the thermal degradation of granulated scrap tires: a model-free analysis”. Materials Science, vol. 19, No. 4, pp. 403-408.

10. Miandad, R., Barakat, M. A., Aburiazaiza, A. S., Rehan, M. and Nizami, A. S. (2016). "Catalytic pyrolysis of plastic waste: A 
review". Process Safety and Environmental Protection, vol. 102, pp. 822-838.

11. Ruwona W., Danha, G. and Muzenda, E. (2019). "A review on material and energy recovery from waste tires". Procedia Manufacturing, vol. 35, pp. 216-222.

12. Sibel Irmak. (2017). "Biomass as Raw Material for Production of High-Value Products". Biomass Volume Estimation and Valorization for Energy, pp. 202-218.

13. Ram Jatan Yadav. Shivam Solanki. Sarthak Saharna. Jonty Bhardwaj and Ramvijay. (2020). "Pyrolysis of Waste Plastic into Fuel”. Bangladesh, vol. 9, ISSN: 22773878. International Journal of Recent Technology and Engineering (IJRTE).

14. Chatziaras, N., Psomopoulos, C. S., \& Themelis, N. J. (2016). Use of waste derived fuels in cement industry: a review. Management of Environmental Quality: an international journal. vol. 27.

15. Mavukwana, A. E., and Sempuga, C. (2020). "Recent developments in waste tire pyrolysis and gasification processes". Chemical Engineering Communications.

16. Aslan, D. I., Parthasarathy, P., Goldfarb, J. L. and Ceylan, S. (2017). "Pyrolysis reaction models of waste tires: Application of Master-Plots method for energy conversion via devolatilization". Waste Management, vol. 68, pp. 405-411.

17. Yaqoob, H., Teoh, Y. H., Jamil, M. A. and Gulzar, M. (2021). "Potential of tire pyrolysis oil as an alternate fuel for diesel engines: A review”. Journal of the Energy Institute, vol. 96, pp. 205-221.

18. Katarzyna Januszewicz Paweł Kazimierski, Kosakowski W., and Lewandowski, W. M. (2020). "Waste tires pyrolysis for obtaining limonene”. Materials, vol. 13, No. 6, pp. 1359.
19. Sathiskumar, C., and Karthikeyan, S. (2019). "Recycling of waste tires and its energy storage application of by-productsa review". Sustainable Materials and Technologies, vol. 22.

20. Shah, P., Kachhadiya, P., and Khirsariya, P. ICCI. (2017).

21. Tavera-Ruiz, C., Gauthier-Maradei, P., Capron, M., Ferreira-Beltran, D., PalenciaBlanco, C., Morin, J. C., and Dumeignil, F. (2019). "An alternative to the cymenes production from scrap tire rubber using heteropoly acid catalysts". Waste and Biomass Valorization, 10 (10), 3057-3069.

22. Oyedun, A. et al., (2012). "Optimization of particle size in waste tire pyrolysis". Fuel, vol. 95 No. 1, pp.417-424.

23. Alsaleh, A. and Sattler, M.L., (2014). "Waste Tire Pyrolysis: Influential Parameters and Product Properties". Current Sustainable/ Renewable Energy Reports, vol. 1No. 4, pp.129-135.

24. Dong, J. et al., 2016. "Effect of Operating Parameters and Moisture Content on Municipal Solid Waste Pyrolysis and Gasification”. Journal of Energy \& fuels, vol. 30, pp.3994-4001.

25. Osayi, J. I., Iyuke, S., Daramola, M. O., Osifo, P., Van Der Walt, I. J. and Ogbeide, S. E. (2018). "Pyrolytic conversion of used tires to liquid fuel: characterization and effect of operating conditions". Journal of Material Cycles and Waste Management, 20(2), 1273-1285.

26. Yazdani, E., Hashemabadi, S. H. and Taghizadeh, A. (2019). "Study of waste tire pyrolysis in a rotary kiln reactor in a wide range of pyrolysis temperature”. Journal of Waste Management, vol. 85, pp. 195-201.

27. Alias, R., and Rafee, A. M. (2020). "Characterization of liquid oil from pyrolysis of waste tire”. Malaysian Journal 
of Chemical Engineering and Technology (MJCET), 3(1), 62-68.

28. Laresgoiti, M. F., Caballero, B. M., de Marco, I., Torres, A., Cabrero, M. A. and Chomón, M. J. (2004). "Characterization of the liquid products obtained in tire pyrolysis". Journal of Analytical and Applied Pyrolysis, vol. 71, No. 2, pp. 917934.

29. Ngxangxa S. (2016). "Development of GCMS methods for the analysis of tire pyrolysis oils". Doctoral dissertation, Stellenbosch: Stellenbosch University.

30. González-González, R. B., Ruiz-Gómez, N., Gea, G., Vazquez-Pinon, M., MartinezChapa, S. O., Caballero, P. and Mendoza, A. (2021). "Valorization of Waste Tires by Pyrolysis and Activation Processes". Applied Sciences, vol. 11, No. 14, pp. 6342.

31. Mariusz, W., Janus, R. and Lewandowski, M., 2020. "Pyrolysis Oil from Scrap Tires as a Source of Fuel Components". Journal of Energy \& fuel, vol. 34, No. 5, pp.59175928.

32. Toteva, V., 2021. "Waste Tires Pyrolysis Oil as a source of energy: methods for refining". Journal of progress in rubber, plastics and recycling technology, vol. 36, No. 2, pp.143-158.

33. Susa, D. and Haydary, J., (2014). "Sulfur distribution in the products of waste tire pyrolysis Sulfur distribution in the products of waste tire pyrolysis". Chemical papers, vol. 67, No. 12, pp.1521-15. 